\title{
MICROPUNCTURE STUDY OF THE FLUID COMPOSITION OF 'SERTOLI CELL-ONLY' SEMINIFEROUS TUBULES IN RATS
}

\author{
NORMAN LEVINE* AND DONALD J. MARSH $\uparrow$ \\ Department of Physiology, New York University School of Medicine, \\ New York, N.Y. 10016, U.S.A.
}

(Received 19th November 1974)

Fluid collected by micropuncture from individual seminiferous tubules of rats contains a potassium ion concentration about ten times greater than that found in plasma, and a sodium ion concentration about 30 mequiv./litre less than that found in plasma (Tuck, Setchell, Waites \& Young, 1970; Levine \& Marsh, 1971). Tuck et al. (1970) also observed that the potassium ion concentration of fluid secreted into oil-filled seminiferous tubules was double that found under normal conditions, and the sodium ion concentration was a third of the value normally found. These authors suggest that the seminiferous epithelium normally secretes a potassium-rich solution (about 100 mequiv./litre) which is mixed in the tubule with a sodium-rich low potassium-containing fluid secreted by the rete testis. Tuck et al. (1970) further postulate that it is the Sertoli cells that are responsible for fluid secretion in seminiferous tubules.

Hemsworth \& Jackson (1963) reported that Busulphan (butane-dimethylsulphonic acid), when injected into pregnant rats on the 13th day after coitus, inhibits the development of the sex cells but not the supporting cells. These authors claimed that the testes of the male offspring contain tubules lined only with Sertoli cells. To achieve some distinction between the relative contributions of the Sertoli cells and the sex cells to the fluid of the seminiferous tubules, we sampled and analysed fluid from individual 'Sertoli cell-only' tubules.

Ten pregnant rats were injected intraperitoneally on the 13th day after coitus with Busulphan $(10 \mathrm{mg} / \mathrm{kg})$. The first day that a vaginal plug was present was taken as Day 0 . The male offspring were allowed to grow for about 90 days, after which the fluid in the seminiferous tubules was sampled by micropuncture. The spermatocrit was measured and the tubular fluid analysed for sodium and potassium concentration. The micropuncture and microanalytical techniques used were identical to those described previously (Levine \& Marsh, 1971). After sampling, the contralateral testis was removed, weighed, and fixed in buffered formalin. The tissue was embedded in paraffin wax, 7- $\mu \mathrm{m}$ sections were cut, stained with eosin-haematoxylin and examined under the light microscope.

\footnotetext{
* Present address: Department of Physiology, New York Medical College, Valhalla, New York, N.Y. 10595, U.S.A.

† Present address: Department of Biomedical Engineering, Graduate School of Engineering, University of Southern California, Calif. 90007, U.S.A.
} 
The results of Busulphan treatment were not uniform. Of the ten litters obtained, only two produced animals with sufficient alteration to be experimentally useful. The remainder had testes that, although smaller than normal, were so well developed that it was not possible to locate tubules without spermatozoa. Even in the two litters that were drastically altered, each testis contained some tubules of normal appearance as well as tubules that contained no spermatozoa. The results of analysis of fluid from these animals is presented in Table 1. Of the five animals used, samples were obtained from tubules in each

Table 1. Spermatocrit and sodium and potassium concentrations in the seminiferous tubule fluid of 90-day-old rats exposed to Busulphan in utero and control rats

\begin{tabular}{|c|c|c|c|}
\hline \multirow[b]{3}{*}{$\begin{array}{l}\text { Sodium (mequiv./litre) } \\
\text { Potassium (mequiv./litre) }\end{array}$} & \multicolumn{2}{|c|}{ Rats exposed to Busulphan } & \multirow{2}{*}{ Control rats* } \\
\hline & $\begin{array}{l}\text { Samples from } \\
\text { tubules without sperm. }\end{array}$ & $\begin{array}{l}\text { Samples from } \\
\text { tubules containing sperm. }\end{array}$ & \\
\hline & $\begin{array}{l}139 \pm 7 \\
4 \cdot 6 \pm 1.9(5)\end{array}$ & $\begin{aligned} 124 \cdot 2 \pm 7 \cdot 3 & (5) \\
35 \cdot 6 \pm 6 \cdot 4 & (5)\end{aligned}$ & $\begin{aligned} 109 \cdot 5 \pm 4 \cdot 5 & (30) \\
46 \cdot 2 \pm 3 \cdot 9 & (28)\end{aligned}$ \\
\hline Spermatocrit & $0 \pm 0$ & $0.076 \pm 0.021(5)$ & $0.203 \pm 0.024(30)$ \\
\hline
\end{tabular}

Values are given as Mean \pm S.E.M. Figures in parentheses are number of animals.

* Data from Levine \& Marsh (1971).

testis that, under microscopic examination, did and did not contain spermatozoa. The potassium concentration in the samples not containing spermatozoa was lower than that measured in samples from normal animals $(P<0.0005)$, as well as lower than the potassium concentration in spermcontaining tubules of Busulphan-treated animals $(P<0.0005)$. The potassium concentration in these latter tubules did not significantly differ from that of normal tubules.

The sodium ion concentration in tubules not containing spermatozoa was significantly greater than that of normal tubules $(P<0.0025)$, while the sodium concentration in sperm-containing tubules of males exposed to Busulphan was intermediate between that of normal tubules and those not containing spermatozoa, and was not significantly different from either. Since the mean spermatocrit for the sperm-containing tubules was significantly lower than for 'normal' tubules of untreated animals $(P<0.0005)$, it would appear that some alteration in spermatogenesis occurred in these tubules.

The epididymides of three animals were also examined. They were found to be extremely small and undeveloped. Microscopic examination of the caput revealed that it was greatly distended with fluid but contained no spermatozoa. We managed to collect fluid from the head of two such altered epididymides. Sodium concentrations were 151 and 148 mequiv./litre while the potassium concentration was 2 mequiv./litre in both. Although these measurements are too few to make any general conclusions, they seem to indicate that the composition of this fluid is very similar to that contained in the 'Sertoli cell-only' tubules. It would also appear that the electrolyte reabsorptive processes that we 
have previously noted (Levine \& Marsh, 1971) between the rete testis and the beginning of the caput were not functional in these rats.

The results presented in this study demonstrate that a functional germinal epithelium is necessary if potassium secretion into the seminiferous tubules is to occur. They do not, however, distinguish between the following two possibilities: (1) the Sertoli cells normally secrete a sodium-rich solution while the sex cells secrete a potassium-rich solution; (2) the Busulphan altered epithelium is not functioning at all and the fluid contained in the tubules is 'pure rete fluid'.

The composition of the fluid contained in tubules not containing spermatozoa was similar in sodium and potassium concentration to that reported by Tuck et al. (1970) for rete testis fluid. The slightly higher potassium concentration in rete fluid (14 versus 4 mequiv./litre) is probably the result of admixture with the potassium-rich fluid normally contained in seminiferous tubules. In addition, rete fluid continues to be elaborated in instances in which spermatogenesis has been drastically reduced (Setchell \& Waites, 1972). It might seem, therefore, that the fluid found in tubules that do not contain spermatozoa is produced in the same region as the rete testis fluid. It is probable, however, that the cells that produce rete fluid are not the Sertoli cells that surround the germinal cells but cells that are found distal to the site of spermatogenesis. Although we are unaware of ultrastructural studies of this altered epithelium, if we assume that the membrane is structurally intact and lined with Sertoli cells that are presumably capable of secretion (light microscopy revealed that the epithelium also contains what appear to be primary spermatogonia), then fluid and electrolyte movement should also occur in the proximal portions of the seminiferous tubule. Perfusion studies of the different regions of normal as well as 'Sertoli cell-only' tubules that are correlated with ultrastructural studies of the anatomy of seminiferous tubules and rete testis should help to delineate the sites and nature of fluid secretion in the testis.

This work was supported by NIH Research Grant AM 06864 and USPHS Training Grant GM-00920 in Physiology.

\section{REFERENCES}

Hemsworth, R. N. \& JACKson, H. (1963) Effect of Busulphan on developing gonad of the male rat. F. Reprod. Fert. 5, 187-194.

Levine, N. \& MARSH, D. J. (1971) Micropuncture studies of the electrochemical aspects of fluid and electrolyte transport in individual seminiferous tubules, the epididymis and the vas deferens in rats. F. Physiol., Lond. 213, 557-570.

Setchell, B. P. \& Wartes, G. M. H. (1972) The effects of local heating of the testis on the flow and composition of rete testis fluid in the rat, with some observations on the effects of age and unilateral castration. F. Reprod. Fert. 30, 225-233.

Tuck, R. R., Setchell, B. P., Wartes, G. M. H. \& Young, J. A. (1970) The composition of fluid collected by micropuncture and catheterization from the seminiferous tubules and rete testis of rats. Pfügers Arch. ges. Physiol. 318, 225-243. 